\title{
Ergenlerde İnternet Bağımlıı̆̆ının Yordayıcı Olarak Duygu Düzenlemedeki Rolü
}

\section{The Role to Predict the Internet Addiction of Emotion Regulation in Adolescents}

\author{
Mustafa ERCENGiz* Ali Haydar ŞAR
}

Öz. Bu araştırmanın amacı ergenlerde duygu düzenlemenin internet bağımlılı̆ını yordama gücünü incelemektir. Araştırmanın çalışma grubu Ağrı ilinde farklı liselerde 2014-2015 öğretim döneminin bahar yarıyılında öğrenim gören yaşları 13 ile 19 arası arasında değişen, 197'si kadın, 229'u erkek toplam 426 ergenden oluşmaktadır. Araştırmada veri toplama aracı olarak İnternet Bağımlılığı Ölçeği ile Ergenlerde Duygu Düzenleme Ölçeği kullanılmıştır. Ergenlerin duygu düzenlemenin internet bağımlılığını yordama gücünün belirlenmesi için Pearson Momentler Çarpımı Korelasyon Analizi, Basit Doğrusal Regresyon ve Hiyerarşik Regresyon Analizi ile incelenmiştir. Analizler sonucunda ergenlerde duygu düzenlemenin internet bağımlılığının \%34'ünü açıkladığı ve dışsal işlevsel duygu düzenleme, dışsal işlevsel olmayan duygu düzenle ve içsel işlevsel olmayan duygu düzenlemenin internet bağımlılığı ile pozitif ilişkili ve içsel işlevsel duygu düzenlemenin internet bağımlılı̆ı ile negatif ilişkili olduğu bulunmuştur. Araştırma sonucunda elde edilen bulgular alan yazınıyla ilişkisi çerçevesinde tartışılmış, araştırmacı ve uygulamacılara öneriler sunulmuştur.

Anahtar Kelimeler: Duygu Düzenleme, İnternet Bağımlılığı.

\begin{abstract}
The aim of this research is to examine the predictive power of internet addiction of emotion regulation in adolescents. The study group is formed from 426 adolescents, ages between 13 and 19, 197 female and 229 male, enrolled at the different high schools in 2014-2015 spring semester in Ağrı. In the research, the Internet Dependency Scale and the Emotion Regulation Scale for Ergens were used to collect data. Pearson Moments Multiplication Correlation Analysis, Simple Linear Regression and Hierarchical Regression Analysis were examined to clarify whether emotional regulation predicts the internet adiction of adolescents. According to results of data, that was found that $34 \%$ of Internet addiction in adolescents was explained by internet addiction, external functional emotion regulation, external non-functional emotion regulation and internal non-functional emotion regulation were related to internet dependencypositively and the internal functional emotion regulation was related to internet dependency negatively. According to results, the findings were discussed in the context of the findings, and researcher and practitioner suggestions were presented.
\end{abstract}

Keywords: Emotional Regulation, Internet Addiction.

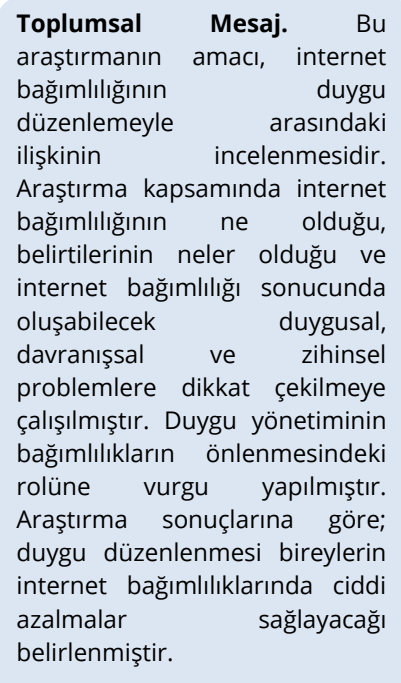

Public Interest Statement. The aim of this research is to examine the relationship between internet addiction and emotion regulation. Within the scope of the research, attention has been paid to the emotional, behavioral and mental problems that may arise as a result of internet dependency, what the symptoms are and internet addiction. Emphasis has been placed on the role of emotion management in the prevention of addictions. According to the results of the research; Emotional regulation has been determined to provide significant reductions in Internet addiction for individuals.

\footnotetext{
*Arş. Gör., Ağrı Ibrahim Çeçen Üniversitesi Eğitim Fakültesi, Eğitim Bilimleri Bölümü, mercengiz@agri.edu.tr

**Doç. Dr., Sakarya Üniversitesi Eğitim Fakültesi, Eğitim Bilimleri Bölümü, asar@sakarya.edu.tr
} 


\section{GiRiş}

Duygu, birey için önemli sayılabilecek durumlar söz konusu olduğunda koşulsal olarak, bazı durumlarda ise neredeyse otomatik olarak ortaya çıkan deneyimsel davranışlar örüntüsü, fizyolojik tepki eğilimleri ve duruma göre tepki geliştirme mekanizması olarak tanımlanmaktadır (Gross, 2002). Werner ve Gross (2010) duyguların var olan durumla uyumlu olmadıklarında, yoğun olduklarında ve çok uzun sürdüklerinde işlevselliklerini kaybedip sorunların yaşanmasına neden olduğunu vurgulamaktadır. Bu bağlamda McLaren, (1998) pilsiz saat nasıl hareketsiz kalıyorsa duygularını düzenlemeyen birey de pilsiz saat gibi fonksiyonlarını yerine getirebilecek enerjiden yoksun kalmaktadır ifadesiyle duygu düzenlemenin önemine dikkat çekmiştir. Duygu düzenleme, bireyin hedeflerini gerçekleştirmesinde de özellikle birey için yoğun ve kalıcı olmayan karakterdeki duygusal tepkilerin izlenmesinde, değerlendirilmesinde ve değiştirilmesinde kullanılan içsel ve dışsal tepki süreçlerinden oluşur (Thompson, 1994). Diğer bir ifadeyle duygu düzenleme, stres, ruh hali ve pozitif veya negatif duyguyu da içeren tüm duygu durumlarının düzenlenmesini kapsamaktadır (Koole, 2010). Bu bağlamda duygu düzenleme, içten veya dıştan gelen duygu ile ilgili ipucunun gözden geçirilmesi ile başlamakta ve bu gözden geçirmenin davranışsal olarak verilecek tepkiyi düzenlenmesiyle sonuçlanmaktadır (Gross, 1998; Gross \& Levenson, 1993).

Son zamanlarda teorik ve ampirik duygu düzenleme yaklaşımları kapsamında deneysel sosyal psikoloji, gelişimsel nörobiyoloji ve davranışsal psikopatoloji gibi alanlarda farklı duygu düzenleme yaklaşımları ortaya çıkmıştır (Fredrickson, Mancuso, Branigan, ve Tugade, 2000; Glynn, Christenfeld, ve Gerin, 2002; Gross, 1998; Melamed, 1996; Schore, 1996; Siegel, 2001). Bu kapsamda duygu düzenleme ile ilgili stratejiler ortak süreç yaklaşımı adı altında ele alınmaktadır. Ortak süreç yaklaşımına göre duygu oluşumu, içsel ve dışsal süreçler sonucunda gelişen ipuçların değerlendirilmesi ile başlamaktadır. Bu değerlendirmenin ise davranışsal, sosyal ve duygusal tepki eğilimini düzenlediği vurgulanmaktadır. Bu modelde duygu düzenleme stratejileri geçmiş odaklı ve tepki odaklı olmak üzere iki farklı düzeyde incelenmiştir. Geçmiş odaklı duygu düzenleme stratejisi, herhangi bir reaksiyonun gelişmeden önce duygusal tepki eğilimini aktif hale getirebilmek, davranışı yeniden değerlendirmek ve psikososyal yanıtla ilgilidir. Tepki odaklı strateji ise herhangi bir reaksiyon oluştuktan sonra, daha önce bir kere oluşturulan duygu ile ilgilidir. (Gross ve John, 2003).

Duygu veya duygu düzenleme ile ilgili problemler, DSM-V'teki psikopatoloji tanı ölçütlerinin \% 75'inden daha fazlasını karşılamaktadır (Thompson ve Goodman, 2010). Duygu düzenlemede yaşanan başarısızlıklar, birçok psikopatoloji türünün karakteristik özelliklerindendir (Gross, 2002). Araştırmalarda duygu düzenlemenin sınır kişilik bozukluğu, travma sonrası stres bozukluğu, panik bozukluk, yaygın anksiyete bozukluğu ile anoreksiya nevroza, bulimiya nevroza ve pika gibi yeme bozukluklarıyla ilişkili olduğu belirlenmiştir (Thompson ve Goodman, 2010; Schreiber ve ark., 2012; Beblo ve ark., 2012; Tull ve Roemer, 2007; Mennin ve ark., 2004; Aldao, Nolen-Hoeksema ve Schweizer, 2010; Bender ve ark., 2012). Ayrıca zayıf duygu düzenleme becerilerinin bireyde impulsif belirtileri arttırdığı saptanmıştır (Schreiber, Grant ve Odlaug, 2012). İmpulsivite, bağımlıı̆̆ın ortaya çıkmasında önemli faktör olarak değerlendirilmektedir (Vitaro, Ferland, Jacques ve Ladouceur, 1998). Bu bağlamda araştırmalarda impulsivitenin maddenin kötüye kullanımında önemli bir risk faktörü olduğu belirlenmiştir (Fox, Berquist, Hong, ve Sinha, 2007). Erken başlangıçlı bağımlılık geliştiren bireylerin geç başlangıçı bağımlılık geliştiren bireylere göre impulsivite oranlarının daha yüksek olduğu birçok çalışmada gösterilmiştir (Dom, D'haene, Hulstjin ve Sabbe, 2006). Ayrıca araştırmalarda impulsivitenin, internet bağımlılı̆̆ının ortaya çıkmasında etkili bir faktör olduğu saptanmıştır (Cao, Su, Liu ve Gao, 2007).

Son zamanlarda bir bağımlılık türü olarak ortaya çıkan internet bağımlılığının standart bir tanımı yapılmamış olmakla birlikte, bir bağımlılık şekli olarak kabul edilmekte ve internet bağımlılı̆̆ı, internetin zararlı ve uzun bir süre kontrol dışı kullanımını olarak tanımlanmaktadır (Grüsser ve Thalemann, 2006; Thalemann, 2010). Literatüre bakıldığında internet bağımlılığı terimi, farklı şekillerde ifade edilmektedir. Bu kapsamda kullanılan bazı terimler ise "Bilgisayar Bağımılı̆̆ı̆, 
"Internet Bağımlıı̆̆ı","Patolojik internet Kullanımı" ve "Problematik internet Kullanımı" olarak kullanılmaktadır (Chou, Condron ve Belland, 2005; Thatcher ve Goolam, 2004). İnternet bağımlılığı; sosyal ve akademik olumsuz sonuçlar oluşturabilen duygusal, bilişsel ve davranışsal anomalileri olan çok boyutlu bir sendrom olarak kavramsallaştırımıştır (Caplan, 2005). En geniş tanımıyla internet bağımlılığı, internette gerekli durumların dışında çok fazla zaman geçirme problemi olarak tanımlanmaktadır (Young, 1996).

İnternet bağımlıı̆̆ının tanımının yapılması amacıyla Young (2007), internet bağımlılı̆ı ölçütlerini belirlemiştir. Internet ile ilgili zihnin aşırı meşgul olunması, internet kullanımından istenilen zevkin alınabilmesi için sürekli artan bir internet kullanım ihtiyacının hissedilmesi, Internet kullanımını kontrol etmeye yönelik düzenlemelerde başarısız olunması, internete ulaşımın aksaması ve ya azalması durumunda huzursuzluk, çökkünlük veya kızgınlık gibi duygusal anomalilerin yaşanması, planlanan internet kullanım süresinin çok daha üzerine çıkılması internetin aşırı kullanımı sonucunda sosyal ve mesleki sorunların yaşanması, sosyal çevreyi oluşturan bireylere (aile, arkadaşlar, terapist vb.) internet kullanım süresi ile ilgili yalan söylenmesi ve İnternetin olumsuz duygu ve düşüncelerden kaçınmak için kullanımı olarak belirlemiş ve bu sekiz ölçütten beşinin karşılanmasını internet bağımlılı̆ı tanısı konulabilmesi için yeterli görmüştür. Young (1996), yukarıda belirtilen kriterlerden beş ya da daha fazlasına "Evet" cevabı verilmesi durumunda bireylerin internet bağımlısı olarak değerlendirilebileceğini kriterlerin beşinden daha azına evet cevabını verenleri ise normal internet kullanıcıları olarak değerlendirilebileceğini belirtmiştir. Young, (1999) internet bağımlılığının gelişiminde etkili olan ödül sitemini ACE (Anonymity, Convenience, Escape) olarak modellemiştir. ACE modeline göre internetin; interaktif alanlara, bilgiye ve pornografik içerikli materyallere erişilebilmesi, özellikle intertnet kullanımında gizliliğin olması ile alternatif benliklerinin yansıtabilcekleri alan bulunması ve internet kullanımının duygusal bunalımlardan kurtulmak amacıyla psikolojik kaçış sağlaması, kullanımında bağımlılığa neden olmaktadır.

Ergenlik döneminde yaşanan kimlik bunalımı, aileden ayrı birey olma gayreti ve bunların getirmiş olduğu ruhsal bunalımlardan kaçma eğiliminde olan ergenler, problemli internet kullanımı için önemli bir risk grubunu oluşturmaktadır (Christensen, Orzack, Babington, ve Patsdaughter, 2001; Widyanto ve McMurran, 2004). Araştırmalarda bilgisayar başında geçirilen zamanla psikopatolojik semptomlar arasında doğrusal bir oranın olduğunu saptanmıştır (Chiu, Lee ve Huang, 2004; Hauge ve Gentile, 2003; Jang, Hwang, ve Chois, 2008). Türkiye'de internet bağımlılığı 2000'li yılların başından itibaren araştırmacıların dikkatini çekmeye başlamıştır. Internet bağımlılığıyla ilgili çalışmalar incelendiğinde hem Türkiye'de hem de yurt dışında internet bağımlılığı ve duygu düzenleme arasındaki ilişkinin incelendiği bir çalışmaya rastlanılmamıştır. Dolaysıyla amacı ergenlerde duygu düzenlemenin internet bağımlıı̆̆ının yordama gücünü araştırmak olan bu araştırmanın, literatür açısından veri birikimine ve özellikle ergenlerde psikopatolojik durumlara neden olduğu yapılan araştırmalarla kanıtlanan internet bağımlılı̆ına müdahale ve internet bağımlılı̆ııı önleme çalışmalarına katkı sağlayacağı düşünülmektedir.

\section{YÖNTEM}

\subsection{Araştırmanın Modeli}

Ergenlerde duygu düzenlemenin internet bağımlılığını yordama gücünün incelendiği bu çalışma ilişkisel tarama modelinde betimsel bir çalışmadır.

\section{2 Çalışma Grubu}

Araştırmanın çalışma grubu Ağrı ilinde farklı liselerde 2014-2015 öğretim döneminin bahar yarıyılında öğrenim gören yaşları 13 ile 19 arası arasında değişen, 197'si kadın, 229'u erkek toplam 426 ergenden oluşmaktadır. Araştırmaya dâhil edilen ergenler basit seçkisiz örnekleme yöntemi ile rastlantısal olarak belirlenmiş olup çalışmada toplanan anketlerden 23 anket formu eksik ve hatalı 
olduğu için analize dâhil edilmemiş. Ölçekler çalışmaya katılmayı gönüllü olarak kabul eden lise öğrencilerine öğrenim gördükleri dersliklerde uygulanmıştır.

\subsection{Veri Toplama Aracı}

Internet bağımlılığı Ölçeği (IBÖ). Hahn ve Jerusalem (2001) tarafından geliştirilen ve Şahin ve Korkmaz (2011) tarafından Türkçeye uyarlanan İnternet Bağımlılı̆ı Ölçeği (IBÖ) bireyin internet bağımlılığı düzeyini ölçmek amacıyla geliştirilen ölçek, 19 madden oluşmakta ve 5'i likert (1=Nadiren, 5=Her zaman) tipi bir ölçektir. Açımlayıcı faktör analizi sonucunda 3 alt boyuttan oluştuğu tespit edilen ölçeğin Kontrol Kaybı" faktörü 7 maddeden oluşmakta ve faktör yükleri .72.84 arasında değişmektedir. "Daha Fazla Online Kalma İsteği" faktörü 4 maddeden oluşmakta ve faktör yükleri .64-.84 arasında değişmektedir. "Sosyal ilişkilerde Olumsuzluk" faktörü ise 8 maddeyi oluşmakta ve faktör yükleri .67 ile .82 arasında değişmektedir. Doğrulayıcı faktör analizi sonucunda internet bağımlılığı modelinin iyi uyum değerlerine sahip olduğu saptanmıştır [ $\chi^{2} \quad(s d=149)=580,17$, $\mathrm{p}<.01, \mathrm{RMSEA}=.079, \mathrm{SRMR}=.045, \mathrm{GFI}=.90 \mathrm{AGFI}=.85, \mathrm{CFI}=.97, \mathrm{NNFI}=.96, \mathrm{IFI}=.95]$. Ölçeğin Cronbach alpha iç tutarlıık katsayıları .89 ile .93 arasında değişmektedir. Ölçekte tersten puanlanan madde bulunmamaktadır. Ölçeğin bütününden toplam puan olarak en düşük 19 en yüksek 95 puan alınabilir. Ölçekten alınan yüksek puanlar internet bağımlılı̆ı düzeyinin yüksek olduğunu ifade etmektedir.

Ergenler İçin Duygu Düzenleme Ölçeği (EIDDÖ). Phillips ve Power (2007) tarafından geliştirilen, Duy ve Yıldız (2014) tarafından Türkçeye uyarlanan Ergenler İçin Duygu Düzenleme Ölçeği'nin (EiDDÖ) Doğrulayıcı faktör analizi sonucunda 18 maddeden ve dört boyuttan oluşan duygu düzenleme modelin iyi uyum verdiği görülmüştür $\left(\chi^{2}=517.94\right.$, sd=129, RMSEA $=.06, \mathrm{RMR}=.09$, SRMR $=.06, \mathrm{GFI}=$ $.94, \mathrm{AGFI}=.92, \mathrm{CFI}=.93, \mathrm{NFI}=.91$ ve NNFI= .92). Ergenler İçin Duygu Düzenleme Ölçeği'nin Cronbach Alfa katsayısı sırasıyla dışsal işlevsel olmayan duygu düzenleme alt boyutu için .76, içsel işlevsel olmayan duygu düzenleme alt boyutu için .68, içsel işlevsel duygu düzenleme alt boyutu için .74 ve dışsal işlevsel duygu düzenleme alt boyutu için .59 olarak bulunmuştur.

\section{4 işlem}

Uygulama esnasında katılımcılara gönüllülük ilkesinin esas olduğu buna göre de soruları yanıtlamak istemeyenlerin araştırmaya katılmalarının zorunlu olmadığı belirtilmiştir. Katılımcıların demografik bilgi formunu ve ölçeklerden oluşan anket bataryalarını doldurmaları ortalama 20-25 dakika sürmüştür. Katılımcıların ölçeklerde yer alan soruları daha rahat yanıtlayabilmeleri için de ölçek bataryalarının üzerine isimlerini yazmamaları istenmiştir. Araştırmadan elde edilen veriler SPSS 20. paket programıyla çözümlenmiştir. Pearson Momentler Çarpımı Korelasyon Analizi, Basit Doğrusal Regresyon ve Hiyerarşik Regresyon Analizi kullanılarak çözümlenmiştir. Analiz yapmaya başlamadan önce analizlerin yapılması için gerekli olan varsayımlar test edilmiştir. Bu bağlamda normallik ve doğrusalık varsayımlarının karşılandığı görülmüştür. Ayrıca değişkenler arasında yüksek bir ilişki görülmemekle birlikte çoklu bağlantı problemi olmadığından emin olmak için Tolerans, VIF ve $\mathrm{Cl}$ değerlerine bakılmıştır çoklu bağlantı probleminin olmadığı bulunmuştur. Veri seti aykırı değerler yönünden incelenmiş Mahalanobis uzaklık değerine sahip olan aykırı değerlerin yer aldığı 11 veri, veri setinden çıkartılmış ve geriye kalan 426 veri ile analizler gerçekleştirilmiştir.

\section{BULGULAR}

Ergenlerde duygu düzenlemenin intertnet bağımlılığını yordama gücünü Pearson Momentler Çarpımı Korelasyon Analizi, Basit Doğrusal Regresyon ve Hiyerarşik Regresyon Analizi ile incelenmiştir. Analiz sonuçları sırasıyla sunulmuştur. 


\subsection{Korelasyon Analizi}

Tablo 1. Değişkenlere Ait Ortalamalar, Standart Sapmalar ve Korelâsyonlar

\begin{tabular}{lccc}
\hline & $\overline{\mathbf{x}}$ & ss & internet Bağımlılı̆̆ \\
\hline Internet Bağım|ı|ı̆̆ı & 37.06 & 19.14 & 1 \\
DiDD & 11.79 & 3.89 & $.18^{* *}$ \\
DiODD & 10.90 & 5.19 & $.53^{\star *}$ \\
iiDD & 15.24 & 3.92 & $-.27^{\star *}$ \\
iiODD & 14.01 & 5.02 & $.39^{* *}$ \\
\hline
\end{tabular}

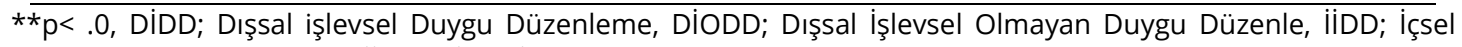
işlevsel Duygu Düzenleme, iïODD; içsel İşlevsel Olmayan Duygu Düzenleme

Tablo 1'de görüldüğü gibi duygu düzenleme ölçeğinin tüm alt boyutları ile internet bağımlılığı arasındaki ikili korelasyonlar anlamlı düzeydedir. Dışsal işlevsel duygu düzenleme ile internet bağımlılığı ( $r=.18)$, dışsal işlevsel olmayan duygu düzenle ile internet bağımlıı̆̆ı $(r=.53)$, içsel işlevsel duygu düzenleme ile internet bağımlılı̆ı $(r=-.27)$ ve içsel işlevsel olmayan duygu düzenleme ile internet bağımlılığı $(r=.39)$ arasında pozitif yönde ve anlamlı ilişkilerin olduğu görülmektedir. Bu bulgular dışsal işlevsel duygu düzenleme, dışsal işlevsel olmayan duygu düzenle ve içsel işlevsel olmayan duygu düzenlemenin internet bağımlılığı ile pozitif ilişkili ve içsel işlevsel duygu düzenlemenin internet bağımlılığı ile negatif ilişkili olduğunu göstermektedir.

\subsection{Regresyon Analizleri}

Tablo 2. Duygusal Düzenleme Ile İnternet Bağımlığı Arasındaki Illişkiye Yönelik Basit Doğrusal Regrasyon Analizi Sonuçları

\begin{tabular}{|c|c|c|c|c|c|}
\hline Yordayan Değişken & $B$ & $\begin{array}{l}\text { Standart } \\
\text { Hata }\end{array}$ & $\beta$ & $t$ & $p$ \\
\hline \multicolumn{6}{|l|}{ Duygu düzenleme } \\
\hline $\begin{array}{l}\text { Dışsal işlevsel duygu } \\
\text { Düzenleme }\end{array}$ & .580 & .202 & .118 & 2.896 & .004 \\
\hline $\begin{array}{l}\text { Dışsal işlevsel olmayan } \\
\text { duygu Düzenle }\end{array}$ & 1.389 & .176 & .377 & 7.891 & .000 \\
\hline $\begin{array}{l}\text { İçsel işlevsel Duygu } \\
\text { Düzenleme }\end{array}$ & -.865 & .207 & .177 & -.4 .181 & .000 \\
\hline $\begin{array}{l}\text { İçsel işlevsel Olmayan } \\
\text { Duygu Düzenleme }\end{array}$ & .687 & .176 & .180 & 3.911 & .000 \\
\hline
\end{tabular}

Tablo 3. Duygusal Düzenlemenin Internet Bağımlıı̆ını Yordamasına Illişkin Hiyerarşik Regresyon Analizi Sonuçları

\begin{tabular}{lccccccc}
\hline $\begin{array}{l}\text { Yordanan } \\
\text { Değişken }\end{array}$ & $\begin{array}{c}\text { Analiz } \\
\text { Aşaması }\end{array}$ & $\begin{array}{c}\text { Yordayan } \\
\text { Değişkenler }\end{array}$ & $\mathrm{R}$ & $\mathrm{R}^{2}$ & $\begin{array}{c}\mathrm{R}^{2 \prime} \text { deki } \\
\text { artış }\end{array}$ & $\begin{array}{c}\text { Yordama } \\
\text { Hatası }\end{array}$ & $\mathrm{F}$ \\
\hline \multirow{2}{*}{ Internet } & 1 & DiODD & .528 & .279 & .277 & 16.27 & 163.86 \\
Bağımlılığı & 2 & iiODD & .549 & .302 & .299 & 16.03 & 91.451 \\
& 3 & iiDD & .569 & .324 & .320 & 15.79 & 67.518 \\
& 4 & DiDD & .581 & .337 & .331 & 15.65 & 53.563 \\
\hline
\end{tabular}

$*{ }^{*} \mathrm{p}<.001$

Tablo 2 incelendiğinde Hiyerarşik Regresyon Analizine sonuçlarına göre dışsal işlevsel olmayan duygu düzenlemenin toplam varyansın \%28'ini $[F(1.424)=163.857 ; p<0.01]$ açıkladığı bulunmuştur. íkinci aşamada içsel işlevsel olmayan duygu düzenlemenin katılması ile toplam varyans \%30'a 
[F(2.423) $=91.451 ; p<0.01]$; üçüncü aşamada içsel işlevsel duygu düzenlemenin katılması ile toplam varyans \%32'ye $[F(3.422)=67.518 ; p<0.01]$; dördüncü aşamada dışsal işlevsel duygu düzenlemenin değişkeniyle \%34'e yükselmiştir [F(4.431)= 19.24; $p<0.01]$. Bir başka ifadeyle, adımsal regresyon analizi sonucunda en önemli yordama katkısının dışsal işlevsel olmayan duygu düzenleme değişkeninden geldiği ve diğer değişkenlerin yordamaya olan katkılarının eşit olduğu anlaşıımaktadır. Çoklu ve hiyerarşik regresyon analizlerine birlikte bakıldığında; internet bağımlılığının \%34'ünü Dışsal işlevsel olmayan Duygu Düzenleme, içsel iş̧levsel Olmayan Duygu Düzenleme, içsel İşlevsel Duygu Düzenleme ve Dışsal İşlevsel Duygu Düzenleme değişkenlerince açıklandığı görülmektedir. Değişkenler ile bağımlılık arasındaki ilişkinin yönüne göre sonuçlara bakıldığında, değişkenlerin artışı internet bağımlılığının artmasına yol açıyor denilebilir.

\section{SONUÇ, TARTIŞMA VE ÖNERILER}

Ergenlerde internet bağımlılı̆ını yordamada duygu düzenlemenin katkısının incelendiği bu çalışmada, internet bağımlılığının, duygu düzenlemenin alt boyutlarından içsel işlevsel duygu düzenleme ile negatif ilişkili olduğu görülmüştür. Araştırmalarda Psikolojik iyi olmanın sağlanmasında önemli olan kavramlardan birinin duyguların farkında olunuşu olduğu görülmektedir (Lane, Quinlan, Schawartz, Walker ve Zeitlin, 1990; Lundh, Johnson, Sundqvist ve Olsson, 2002; Winkelman, 2000). Duygunun özellikle, kendini koruma, motive olma, karar verme, harekete geçme gibi durumlarda etkili olduğu (Çeçen, 2002) göz önünde bulundurulduğunda, duyguların farkında olunuşu psikolojik iyi olma için önemli olduğu söylenebilir. Duygu, bireyin dışsal uyarıcılarla ilgili algılamaları ve değerlendirmeleri neticesinde oluşan iç yaşantılardır (Lazarus, 1982). Bu iç yaşantıların psikolojik iyi olmayı arttırması amacıyla kullanılabilmesi için duygusal farkındalığın ve duyguları ifade edebilmenin önemli olduğu düşünülebilir. Duygusal farkındalık, bireyin duygularını tanıma yetisi olarak tanımlanmaktadır (Lane ve ark. 1990). Bu bağlamda duygusal farkındalığın, duygusal düzenleme stratejilerinden duyguların farkına varma ve yeniden düzenlenmesi kapsamında değerlendirilebileceği söylenebilir. Duygusal düzenleme stratejilerinde elde edilen başarılar bağımlılıkların geliştirilmesinde negatif bir rol oynadığı araştırmalarla sabittir (Heckman, Ditre ve Brandon, 2012; Thompson ve Goodman, 2010; Schreiber, Grant ve Odlaug, 2012) dolaysıyla araştırma neticesinde içsel işlevsel duygusal düzenleme boyutunun internet bağımlılı̆ıyla negatif yönlü ilişki olduğunun bulunması literatür sonuçlarını desteklemektir. Yine aynı bağlamda literatür taraması yapıldığında bağımlılık ile öz denetim arasında kuvvetli ilişkilerin olduğu görülmektedir (Gottfredson ve Hirschi, 1990; Kim ve ark., 2008; Niemz ve diğ., 2005; Trimmel ve Kopke, 2000 ). Öz-denetim, bireyin içsel tepkilerini bastırma ya da değiştirme becerisinin yanı sıra istenmeyen davranışsal eğilimleri bölme ve olumsuz davranımların sergilenmesinin engellenmesidir (Tangney, Baumeister ve Boone, 2004). Öz denetimi düşük bireyler; ımpulsivite, maddenin kötüye kullanımı ve davranışlarını kontrol etmede ciddi problemler yaşamaktadır ve öz denetim eksikliği, bağımlılıkların gelişiminin pozitif yönde kuvvetli bir yordayıcısıdır (Gottfredson ve Hirschi, 1990; Kim ve ark., 2008; Niemz ve diğ., 2005; Trimmel ve Kopke, 2000 ). Yine aynı bağlamda Slater'a (2003) göre öz denetimi düşük olan bireylerin internet bağımlılı̆̆ına eğilimleri yüksektir. Öz denetimin, duygu düzenlemede çok önemli pozitif yönde bir etkisi söz konusudur (Zemack, 2006). Öz denetimin düşük olması bireylerin bağımlılık geliştirmesinde kuvvetli bir etken olması (Gottfredson ve Hirschi, 1990; Kim ve ark., 2008; Niemz ve diğ., 2005; Trimmel ve Kopke, 2000 ) ve öz denetimin duygu düzenlemede çok önemli pozitif yönde bir etkisi söz konusu (Zemack, 2006) olması dolaysıyla duygu düzenlemenin bağımlılık gelişiminde negatif yönlü bir etkisi olduğu söylenebilir. Bu bağlamda araştırmanın sonucu literatür taraması neticesiyle varılan sonuçlarla paralel bir ilişki göstermektedir.

Araştırmada internet bağımlıı̆ının, içsel işlevsel olmayan duygu düzenleme ve dışsal işlevsel olmayan duygu düzenleme ile pozitif ilişkili olduğu bulunmuştur. Araştırmanın sonucuna göre işlevsel olmayan duygu düzenlemenin internet bağımlılığının gelişiminde pozitif yönde bir etkisi olduğu söylenebilir. Bu bağlamda literatür taramaları sonucunda ulaşılan araştırmalarda zayıf 
duygu düzenleme becerileri bireyde ımpulsivite riskini arttırması (Schreiber, Grant ve Odlaug, 2012) ve ımpulsivitenin bağımlılık geliştirilmesinde önemli bir risk etkeni olması (Vitaro, Ferland, Jacques ve Ladouceur, 1998) göz önüne alındığında duygu düzenlemede yaşanan işlevsizliklerin bağımlılığın gelişimini pozitif yönde etkilediği çıkarımında bulunulabilir. Dolaysıyla literatür taraması neticesiyle elde edilen sonuçlar, araştırmanın sonucuyla benzerlik gösterdiği söylenebilir. Yine aynı bağlamda Duygusal düzenleme stratejilerinde elde edilen başarılar, bağımlılıların geliştirilmesinde negatif bir rol oynamaktadır (Heckman, Ditre ve Brandon, 2012; Thompson ve Goodman, 2010; Schreiber, Grant ve Odlaug, 2012). Bu bağlamda duygusal düzenlemede yaşanan başarısızlıkların bağımlıı̆ın gelişiminde pozitif rol oynadığı söylenebilir. Dolaysıyla araştırmadan edinilen bulguların literatür sonuçlarını desteklediği söylenebilir.

Araştırmada dışsal işlevsel duygu düzenleme ile internet bağımlılı̆ı arasında pozitif yönlü bir ilişki olduğu bulunmuştur. Araştırma kapsamında yapılan literatür taraması neticesiyle öz kontrolün, davranışların kontrol edilmesinde önemli bir etken olduğu görülmektedir ( Davis, 2001). Yapılan araştırmalarda bağımlıı̆̆ın en önemli sebeplerinden birisi olarak davranış kontrol eksiliği olarak görülmektedir (Gailliot ve Baumeister, 2007). Yine aynı bağlamda düşük kontrolün, bağımlılıklara sebep olduğu ifade edilmektedir (Gottfredson ve Hirschi, 1990). Dışsal işlevsel duygu düzenleme kavramının faklı bir ifadesi olduğu düşünülen davranışın kontrolünde yaşanan zafiyetler neticesiyle bağımlılık davranışlarının arttı̆̆ı söylenebilir. Dolaysıyla araştırmada alınan dışsal işlevsel duygu düzenleme ile internet bağımlıı̆̆ı arasındaki pozitif yönlü ilişki bulunması literatür sonuçlarıyla tersi yönde bir bulgu olduğu söylenebilir. Araştırma sonucunda elde edilen dışsal iş̧levsel duygu düzenleme boyutuyla internet bağımlılı̆ı arasında pozitif yönlü ilişki araştırma kapsamında kullanılan Ergenler iç̧in Duygu Düzenleme Ölçeği'nin (EiDDÖ) dışsal işlevsel duygu düzenleme alt boyut maddeleri "Bu olaya ilişkin neler hissettiğimi birisiyle konuşurum, Arkadaş/arımdan veya ailemden sarılmak, elini tutmak gibi bedensel yakınlık ararım, Hareketli bir şeyler yaparım, Başkalarından tavsiye isterim" göz önünde bulundurularak incelendiği takdirde dışsal işlevsel duygu düzenleme alt boyutunun ölçümünde kullanılan maddelerin bireylerin duygularını düzenlemesi amacıyla başka bireylerin sosyal desteklerine ihtiyaç duyduğu temel anlayışından yola çıkıldığı varsayılabilir. Belirtilmiş olan varsayım ışığında dışsal işlevsel duygu düzenleme ile internet bağımlılığı arasında pozitif yönlü ilişki sonucu yeniden değerlendirilebilir. Sosyal destek; bireyin gereksinim duyduğunda çevresinden elde edebileceği duygusal, bilişsel ve sosyal yardımları kapsamaktadır (Cohen, 2004; Cohen ve Wills, 1985). Sosyal destek, bireylerin psikolojik ve fiziksel intiyaçlarının karşılanarak bireylerin sevgi ve saygı görme gibi psikolojik anlamda ihtiyaçlarını karşılayan bir sistem olarak tanımlanabilir (Aksüllü, 2004; Tan ve Karabulut, 2005). Modern toplumlarda yaşanan kapitalist sistem içinde egemen bir ideoloji olarak bireyselliğin artması gibi süreçler reel dünyadaki insan ilişkilerini tartışılır hale getirmiştir (Pahl, 2000; Yanıklar, 2011). Reel dünyadaki ilişkilerin tartışıı hale gelmesi, hiç kuşku yok ki bireylerin sosyal destek ihtiyaçlarının karşılanmasındaki (dedikodu yapmak, flört etmek vs ) ilgi odaklarının sanal ortama çevrilmesine neden olmaya başlamıştır (Ridings ve Gefen, 2004). Reel dünyaya olan ilgi odağının sanal dünyaya çevrilmeye başlanması üzerine sanal topluluklar oluşmaya başlamıştır (Ridings ve Gefen, 2004). Oluşan sanal topluluklarda reel dünyadaki sosyal destek ihtiyacının karşılanmaya çalışılması, bireylerin internette daha fazla zaman geçirmelerine neden olduğu söylenebilir. Dolaysıyla internette geçirilen zaman ile internet bağımlılığının pozitif yönlü ilişkisi olduğu (Young, 1999) göz önüne alındığında araştırmanın dışsal işlevsel duygu düzenleme ile internet bağımlılığı arasında pozitif yönlü bir ilişkinin bulunması literatür sonuçlarıyla paralellik gösterdiği varsayılabilir. 


\section{Kaynakça}

Aksüllü, N. (2004). Huzurevinde ve Evde Yaşayan Yaşlılarda Algılanan Sosyal Destek Etkenleri ile Depresyon Arasındaki İlişki. Anadolu Psikiyatri Dergisi, 5, 76-85.

Aldao, A., Nolen-Hoeksema, S. ve Schweizer, S. (2010). Emotion-Regulation Strategies Across Psychopathology: A Meta-Analytic Review. Clinical Psychology Review, 30(2), 217-237.

Beblo, T., Fernando, S., Klocke, S., Griepenstroh, J., Aschenbrenner, S. ve Driessen, M. (2012). Increased Suppression of Negative and Positive Emotions in Major Depression. Journal Of Affective Disorders, 5, 1-6.

Bender, P. K., Reinholdt-Dunne, M. L., Esbjørn, B. H. ve Pons, F. (2012). Emotion Dysregulation and Anxiety in Children and Adolescents: Gender Differences. Personality and Individual Differences, 53(3), 284- 288.

Cao, F., Su, L., Liu, T. ve Gao, X. (2007). The Relationship Between Impulsivity and Internet Addiction in a Sample of Chinese Adolescents. European Psychiatry, 22, 466-471.

Caplan, S. E. (2005). A Social Skill Account of Problematic Internet Use. The Journal of Communication, 55 (4), 736.

Chiu, S., Lee, J.Z. ve Huang, D. H. (2004). Video Game Addiction in Children and Teenagers in Taiwan. Cyberpsychology \& Behavior, 7(5), 571-581

Chou, C., Condron, L. ve Belland, J. C. (2005). A Review of The Research on Internet Addiction. Educational Psychology Review, 17, 363-388.

Christensen, M. H., Orzack, M. H., Babington, L. ve Patsdaughter, C. A. (2001). When the Monitor Becomes the Control Center: Computer Addiction. Journal of Psychosocial Nursing, 39 (3), 40-47.

Conference, April 2003, Tampa, FL. Http://Www.Psychology.lastate.Edu/FACULTY/Dgentile ISRCD\%20Video\%20Game\%20Addiction.Pdf Adresinden 02.03.2014 Tarihinde Erişilmiştir.

Cohen, S. (2004). Social relationships and health. American psychologist, 59(8), 676.

Cohen, S. ve Wills, T. A. (1985). Stres, Social Support, and the Buffering Hypothesis. Psychological Bulletin, 98 (2), 310-357.

Çeçen, R. (2002). Duyguları Yönetme Becerileri Eğitimi Programının Öğretmen Adaylarının Duyguları Yönetme Becerileri Üzerindeki Etkisi. Yayımlanmamış Doktora Tezi, Çukurova Üniversitesi, Sosyal Bilimler Enstitüsü, Adana.

Davis, R. A. (2001). A Cognitive-Behavioral Model of Pathological Internet Use. Computers in Human Behavior, 17. 187-195.

Deci E. L. ve R.M. Ryan, Handbookof Self-Determination Research. Rochester, NY: Univ. Rochester Press, 2002.

Dom, G., D'haene, P., Hulstijn, W. ve Sabbe, B. (2006). Impulsivity in Abstinent Early- and Late-Onset Alcoholics: Differences in Self-Report Measures and A Discounting Task. Addiction, 101, 50-59.

Fox, H. C., Berquist, K. L., Hong, K. I. ve Sinha, R. (2007). Stress-Induced and Alcohol Cue-Induced Craving in Recently Abstinent Alcohol Dependent Individuals. ACER, 31(3), 395-403.

Fredrickson, B. L., Mancuso, R. A., Branigan, C. ve Tugade, M. M. (2000). The Undoing Effect of Positive Emotions. Motivation and Emotion, 24, 237-258.

Gailliot, M. T. ve Baumeister, R. F. (2007). The Physiology Of Willpower: Linking Blood Glucose To SelfControl. Personality and Social Psychology Review, 11, 303-327

Glynn, L. M., Christenfeld, N. ve Gerin,W. (2002). The Role of Rumination in Recovery From Reactivity: Cardiovascular Consequences of Emotional States. Psychosomatic Medicine, 64, 714-726

Gottfredson, M. ve Hirschi, T. (1990). General Theory of Crime. Stanford, CA: Stanford University Press.

Gross, J. (2002). Emotion Regulation: Affective, Cognitive, and Social Consequences. Psychophysiology, 39, 281- 291. 
Gross, J. J. (1998). The Emerging Field af Emotion Regulation: An Integrative Review. Review of General Psychology, 2, 271-299

Gross, J. J. (2002). Emotion Regulation: Affective, Cognitive, and Social Consequences. Psychophysiology, 39 (3), 281-291.

Gross, J. J. ve John, O. P. (2003). Individual Differences in Two Emotion Regulation Processes: Implications for Affect, Relationships, and Well-Being. Journal of Personality and Social Psychology, 85, 348-362.

Gross, J. J. ve Levenson, R. W. (1993). Emotional Suppression: Physiology, Self-Report, and Expressive Behavior. Journal of Personality and Social Psychology, 64, 970-986.

Grüsser, S. M. Thalemann, R. (2006). Computerspielsüchtig?. Bern: Hans Huber Verlag.

Hauge, M.R. ve Gentile, D.A. (2003). Video Game Addiction Among Adolescents: Associations with Academic Performance and Aggression. Presented at Society for Research in Child Development.

Heckman. B. W, Ditre. J. W. ve Brandon, T. H. (2012). The Restorative Effects of Smoking Upon Self-Control Resources: A Negative Reinforcement Pathway. Journal of Abnormal Psychology, 121, 244-249.

Jang KS, Hwang SY, Chois JY. (2008). Internet Addiction and Psychiatric Symptoms Among Korean Adolescents. Journal of School Health, 78, 165-171.

Kim E J, Namkoong K, Ku, T. ve Kim, S. J. (2008). The Relationship Between Online Game Addiction and Aggression, Self-Control and Narcissistic Personality Traits. European Psychiatry. 23, 212-218.

Koole, S. L. (2010). The psychology of Emotion Regulation: An Integrative Review. (In J. D. Houwerand ve D. Hermans (Eds), Cognition and Emotion: Reviews of Current Research and Theories (128-167). NewYork: Taylor \& Francis Group.

Lane, R. D., Quinlan, D. M., Schawartz, G. E., Walker, P. A. ve Zeitlin, S. B. (1990). The Levels of Emotional Awareness Scale: A Cognitive Developmental Measure Of Emotion. Journal of Personality and Assessment, 55 (1/2), 124-134.

Lazarus, R. S. (1982). Thoughts on the Relation Between Emotion and Cognition. American Psychologist, 37, 1019-1024.

Lee, H.W., Choi, J.S., Shin, Y.C., Lee, J.Y., Jung, H.Y. ve Kwon, J.S. (2012). Impulsivity in Internet Addiction: A Comparison with Pathological Gambling. Cyber Psychology, Behavior, and Social Networking, 15, 373-377.

Lundh, L. G., Johnsson, A., Sundqvist, K. ve Olsson, H. (2002). Alexithymia, Memory of Emotion, Emotional Awareness, and Perfectionism. Emotion, 2 (4), 361-379.

Mazhari, S. (2012). Association Between Problematic Internet Use and Impulse Control Disorders Among Iranian University Students. Cyber Psychology, Behavior, And Social Networking, 15, 270-273.

Mclaren, C. (1998). Channeling Your Emotions, http://innerself.com/

Melamed, S. (1996). Emotional Reactivity, Defensiveness, and Ambulatory Cardiovascular Response at Work. Psychosomatic Medicine, 58, 500-507.

Mennin, D. S., Heimberg, R. G., Turk, C. L. ve Fresco, D. M. (2004). Preliminary Evidence for an Emotion Dysregulation Model of Generalized Anxiety Disorder. Behaviour Research and Therapy, 43, 12811310.

Niemz, K., Griffiths, M. ve Banyard, P. (2005). Prevalence of Pathological Internet Use Among University Students and Correlations with Self-Esteem, the General Health Questionnaire (GHQ), and Disinhibition. Cyberpsychology \& Behavior, 8 (6), 562-570.

Pahl, R. (2000) On Friendship, Malden, MA: Blackwell Publishers Inc.

Rıdıngs, C. M. ve D. Gefen. (2004). Virtual Community Attraction: Why People Hang Out Online, Journal of Computer-Mediated Communication, 10 (1).

Schore, A. N. (1996). Effects Of A Secure Attachment Relationship on Right Brain Development, Affect Regulation, and Infant Mental Health. Infant Mental Health Journal, 22, 269-276.

Schreiber, L. R. N., Grant, J. E. ve Odlaug, B. L. (2012). Emotion Regulation and Impulsivity in Young Adults. Journal of Psychiatric Research, 46, 651-658. 
Siegel, D. J. (2001). Toward An Interpersonal Neurobiology Of The Developing Mind: Attachment Relationships, "Mindsight," And Neural Integration. Infant Mental Health Journal, 22, 67-94.

Tan M. ve Karabulutlu E. (2005). Social Support and Hopelessness in Turkish Patients with Cancer. Cancer Nursing, 28, 236-240.

Thalemann, C. (2010). Pathologische Computernutzung Bei Schülern Verschiedener Schultypen Der 8. Und 10. Klassenstufe. Dissertation. Aus Dem Institut Für Medizinische Psychologie Der Medizinischen Fakultät Charité - Universitätsmedizin Berlin.

Thatcher, A. ve Goolam, S. (2004). Development and Psychometric Properties of the Problematic Internet Use Questionnaire. South African Journal of Psychology, 35(4). 793-809.

Thompson, R. A. (1994). Emotion Regulation: A Theme in Search of Definition. Monographs of the Society for Research in Child Development, 59, 25-52.

Thompson, R. A. ve Goodman, M. (2010). Development of Emotion Regulation. Ed.: A. M. Kringand and D. M. Sloan, Emotion Regulation and Psychopathology: A Transdiagnostic Approach to Etiology and Treatment (38-58). New York: The Guilford Press.

Trimmel, M. ve Kopke, E. (2000). Motivations to Control Drinking Behavior in Abstainers, Moderate and Heavy Drinkers Pharmacology Biochemistry Behavior. 66, 169- 174.

Tull, M. T. ve Roemer, L. (2007). Emotion Regulation Diffi Culties Associated with the Experience of Uncued Panic Attacks: Evidence of Experiential Avoidance, Emotional Nonacceptance, ond Decreased Emotional Clarity. Behavior Therapy, 38 (4), 378-391.

Vitaro, F., Ferland, F., Jacques, C. ve Ladouceur, R. (1998)Gambling, Substance Use and İmpulsivity During Adolescence. Psychol Addict Behavior, 12, 185-194.

Werner, K. ve Gross, J.J. (2010). Emotion Regulation and Psychopathology: A Conceptual Framework. In A. Kring ve D. Sloan (Eds.), Emotion Regulation and Psychopathology. (13-37) New York: Guilford Press.

Widyanto L. ve Mcmurran M. (2004). The Psychometric Properties of the Internet Addiction Test. Cyberpsychology, 7, 443-50. York: Taylor \& Francis Group. Emotion Regulation: Affective, Cognitive, and Social Consequences.

Yanıklar, C. (2011). Beyaz Yakalı Orta Sınıfın Toplumsal Ağları Üzerine Bir Çözümleme. Sosyoloji Araştırmaları Dergisi, 14 (2), 152-183.

Young, K. S. (1996). Internet Addiction: The Emergence of A New Clinical Disorder. Cyberpsychology \& Behavior, 3, 237-244.

Young, K. S. (1999). Evaluation and Treatment of Internet Addiction. In L. Vandecreek ve T. Jackson (Eds.), Innovations in Clinical Practice: A Sourcebook ,17, 19-31. Sarasota, FL: Professional Resource Press.

Young, K. S. (2007). Cognitive Behaviour Therapy with Internet Addicts: Treatment Outcomes and Implications. Cyberpsychology \& Behavior, 10, 671-679. 


\section{Extended Summary}

Emotion has been defined as physiological response tendencies, reaction development mechanism according to the situation and experiential behavior pattern which appears conditionally when it is concerned the situation that is important for the individual or nearly automatically in some other conditions (Gross, 2002). Werner and Gross (2010) underline they lose their functions and cause to have problem when emotions are not coherent with present condition, are intensive and last long. In this context, McLaren (1998) takes attention to the importance of regulation of emotions stating that the individual who doesn't regulate his emotions becomes devoid of energy fulfilling their functions just like a clock without battery. Emotion regulation consists of internal and external reaction processes used in realization of the individual's goals, especially in pursuing, evaluating and changing individual's emotional reactions that have not got intense and stable features (Thompson, 1994).

Recently, various emotion regulation approaches have emerged within the scope of theoretical and empirical regulatory approaches in the areas such as experimental social psychology, developmental neurobiology and behavioral psychopathology (Fredrickson, Mancuso, Branigan, and Tugade, 2000; Glynn, Christenfeld, ve Gerin, 2002; Gross, 1998; Melamed, 1996; Schore, 1996; Siegel, 2001).

Failures in emotion regulation are one of characteristic features of many type of psychopathology (Gross, 2002). Researches have founded that emotion regulation is related with borderline personality disorder, posttraumatic stress disorder, panic disorder, common anxiety disorder, Anorexia nervosa, bulimia nervosa and pica Thompson and Goodman, 2010; Schreiber and ark., 2012; Beblo and ark., 2012; Tull ve Roemer, 2007; Mennin ve ark., 2004; Aldao, Nolen-Hoeksema ve Schweizer, 2010; Bender and ark., 2012). Besides, it has been determined that weak emotion regulation skills increases individual's impulsive the symptoms Schreiber, Grant ve Odlaug, 2012). It has been evaluated as an important factor in appearance of impulsive addiction (Vitaro, Ferland, Jacques and Ladouceur, 1998).

Although the definition of internet addiction which emerges as a type of addiction recently has not been made, it is accepted as an addiction and defined as usage of internet a long time and harmful, without control (Grüsser and Thalemann, 2006; Thalemann, 2010).

Internet addiction has taken researchers attention since the beginning of 2000's in Turkey. When the studies on internet addiction has been analyzed, the relation between internet addiction and emotion regulation has not been surveyed neither in Turkey nor other countries yet. Thus, this research whose aim is to search whether emotion regulation of teenagers are predictor of internet addiction is thought that it will be contribute to intervention and prevention studies in the scope of internet addiction and data accumulation in terms of literature.

This study has been maintained in terms of the issues mentioned above. This study searching whether emotion regulation of teenagers are predictor of internet addiction is a descriptive study in the relational search model. The sample created within the scope of the research consists of totally 426 teenagers who are 197 female and 229 male, studies in different high schools in 20162017 educational and training year and whose ages are between 13 and 19. The Internet Addiction Scale and The Emotion Regulation scales were used as data collection tool in the research.

Developed in order to measure the level of individual's internet addiction by Hahn and Jerusalem (2001) and adapted to Turkish language by Şahin and Korkmaz (2011)The Internet Addiction Scale consists of 19 items and is a Likert type scale.

Emotion Regulation Scale for Teenagers (ERT). Developed by Phillips ve Power (2007) and adapted to Turkish language by Duy ve Yıldız (2014) Emotion Regulation Scale for Teenagers (ERT) consists of 18 items and sub-dimensions.

It has been declared that volunteerism is the basic principle so it is not obligatory to join the research for those who are not willing to attend to the study. Participants' filling demographic 
information form and survey batteries consisting of scales lasted approximately 20-25 minutes. It was asked not to write their names on scale batteries so as to participants can answer questions freely. The data obtained in the research was analyzed by SPSS 20. Packet programme. It was resolved using Pearson Moments Multiplication Correlation Analysis, Simple Linear Regression and Hierarchical Regression Analysis. Before starting analyzing, hypothesis that are necessary for analyzing were tested. In this context, it is determined that normality and linearity assumptions were met. As well as there is no high relation among variables, Tolerance, VIF and $\mathrm{Cl}$ values were checked in order to be sure that there is not multiple connection problem and it was determined that that there is not multiple connection problem. Data sets were examined in terms of outliers, 11 data on outliers with Mahalanobis distance value were removed from data sets, the analyze were carried out with the rest 426 data.

Whether emotion regulation of teenagers predicts the internet addiction was analyzed via Pearson Moments Multiplication Correlation Analysis, Simple Linear Regression and Hierarchical Regression Analysis. According to the results of the analyze, The dual correlations between all subscales of emotion regulation scale and internet addiction are in significant level. It was determined that there were positive and significant relations among external functional emotion regulation and internet addiction $(r=.18)$, external non-functional emotion regulation and internet addiction $(r=$ .53), internal functional emotion regulation and internet addiction $(r=-.27)$ and intrinsic nonfunctional emotion regulation and internet addiction $(r=.39)$. These findings showed that externally functional emotion regulation, external non-functional emotion regulation and internally non-functional emotion regulation are positively correlated with internet dependence and internal functional emotion regulation is negatively associated with internet dependence.

According to the results of Hierarchical Regression Analysis, it was founded that external nonfunctional emotion regulation explains $\% 28$ of total variance $[F(1.424)=163.857 ; p<0.01]$. In the second stage, the total variance increased to $30 \%[F(2.423)=91.451 ; p<0.01]$ with participation of the internal nonfunctional emotion regulation; in the third stage, the total variance increased to $32 \%[F(3.422)=67.518 ; p<0.01]$ with the inclusion of the internal functional emotion regulation; in the fourth stage, it increased to $34 \%[F(4.431)=19.24 ; p<0.01]$ with the external functional emotion regulation. In other words, it is understood that the most significant contribution in the stepwise regression analysis results comes from the external nonfunctional emotion regulation variable, and that the contributions of the other variables to the procedure are equal. When we look at multiple and hierarchical regression analyzes together; it is seen that 34\% of internet addiction is explained by the variables of External Nonfunctional Emotion Regulation, Internal Nonfunctional Emotion Regulation, Internal Functional Emotion Regulation, and External Functional Emotion Regulation. When we look at the results according to the relation between variables and dependency, it can be said that the increase of variables leads to the increase of internet dependency. 